\title{
A Fuzzy mathematical model to estimate the effects of global warming on the vitality of Laelia purpurata orchids
}

\author{
Fernando Ferrari Putti ${ }^{\mathrm{a}, *}$, Luis Roberto Almeida Gabriel Filho ${ }^{\mathrm{a}}$, \\ Camila Pires Cremasco Gabriel ${ }^{a}$, Alfredo Bonini Neto ${ }^{a}$, Carolina dos Santos Batista Bonini ${ }^{\text {b }}$, \\ André Rodrigues dos Reis ${ }^{\text {a }}$
}

a School of Science and Engineering, UNESP - São Paulo State University, Postal Code 17602-496, Tupã, SP, Brazil

${ }^{\mathrm{b}}$ School of Agricultural Sciences and Technology, UNESP - São Paulo State University, Postal Code 17900-000, Dracena, SP, Brazil

\section{A R T I C L E I N F O}

\section{Article history:}

Received 19 October 2016

Revised 17 January 2017

Accepted 16 March 2017

Available online 18 March 2017

\section{Keywords:}

Ecology

Global warming

Management

Orchidaceous

Shade

\begin{abstract}
A B S T R A C T
This study aimed to develop a fuzzy mathematical model to estimate the impacts of global warming on the vitality of Laelia purpurata growing in different Brazilian environmental conditions. In order to develop the mathematical model was considered as intrinsic factors the parameters: temperature, humidity and shade conditions to determine the vitality of plants. Fuzzy model results could accurately predict the optimal conditions for cultivation of Laelia purpurata in several sites of Brazil. Based on fuzzy model results, we found that higher temperatures and lacking of properly shading can reduce the vitality of orchids. Fuzzy mathematical model could precisely detect the effect of higher temperatures causing damages on vitality of plants as a consequence of global warming.
\end{abstract}

(c) 2017 Elsevier Inc. All rights reserved.

\section{Introduction}

The effects of global warming are increasing water shortages, prolonged droughts, environmental degradation, and species extinction. Thus, several biomes are presenting disastrous and irreversible effect in response to droughts and high temperatures. In Brazil, there are thousands of orchid species growing in different environmental conditions. Laelia purpurata is an orchid specie showing capability to grown widely in several sites of Brazil. Orchids are focus of many studies, since they have high economic value due to their cultivation be complex and require investments [5]. Willmer [24] observed that increase in atmospheric temperature during spring orchid plants are not properly pollinated by bees; which could affect fertilization and the future of the species. In addition, Robbirt et al. [18] reported that higher temperatures affect negatively the flight distance of bees. Several species of orchids grow naturally far away from trees and could be not properly pollinated by bees. Another concern is related to longterm drought affecting severely the vitality and survival of orchid species $[20,21]$.

Barman and Devadas [3] concluded that high intra-seasonal rainfall variability, high temperature, and the lack of adaptive ca-

\footnotetext{
* Corresponding author.

E-mail address: fernandoputti@tupa.unesp.br (F.F. Putti).
}

pacities are the major limiting factors for extinction of thousands of orchid species across the world. Since the effects go beyond the temperature increase, as well as air humidity changes, heavy rains and frost. In this regard, Prato [16] developed a fuzzy system to analyze the capacity of resistance of protected natural areas in response to climatic changes. In order to optimize the water resource, Giusti and Marsili-Libelli [11] developed a fuzzy model to determine the optimal water replacement rate during prolonged droughts. Several applications can be highlighted, such as change in coastal lines in Taiwan [6] and impacts on corn crop cultivation [22]. Putti et al. [17] used fuzzy logic to evaluate the vitality of Catasetum fimbriatum growing in different environment conditions.

This study aimed to develop a fuzzy rule-based model to evaluate the effects caused by temperature variation, humidity, and shading on the vitality of Laelia purpurata orchid. In addition, we evaluated and recommend the most appropriate sites in Brazil based on climate information for cultivation of Laelia purpurata.

\section{Materials and methods}

From the literature review regarding the cultivation of Laelia purpurata orchid, it was found the edaphoclimatic conditions that most affect their cultivation. The main environmental factors that affect the cultivation of orchids are humidity, temperature and shading conditions. The appropriate management of these edaphoclimatic conditions can result on the best vitality of plants. 


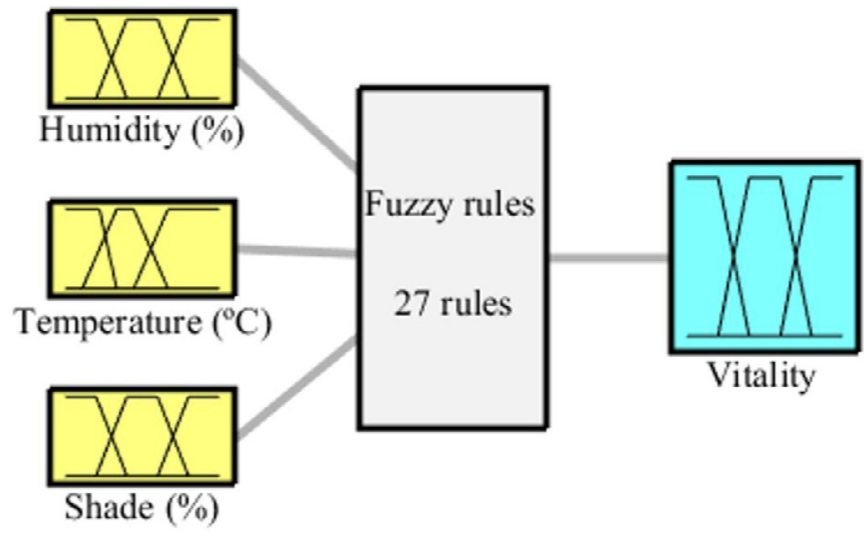

Fig. 1. System based on fuzzy rules to determining the vitality of Laelia purpurata.

In this study, we performed a fuzzy mathematical model to evaluate the effect of climate on orchid physiology and establish the best sites of Brazil for its cultivation based on climate conditions. The experimental data to perform modeling are described according to Watanabe [23].

The mathematical model that includes such features are be described as a function where $f: \mathbb{R}^{3} \rightarrow \mathbb{R}$ with $=f(\bar{x})$, where $\mathbb{R}$ is the set of real numbers, $x_{1}=$ humidity, $x_{2}=$ temperature, $x_{3}=$ shade, and $y=$ vitality (Fig. 1).

The input variables of fuzzy model adopted were humidity, temperature, and shade. The fuzzy sets are composed by three relevance functions (MFs), of trapezoidal type in all impute variables. According to Yeh [25], such adjustment is more accurate. Eq. (1) represents the fuzzy set of the trapezoidal type, which is formed by four points (a, b, c, d). Thus, the modeling number ( $\mathrm{x}$ ) can be contained in 3 parts of the fuzzy set. The first number located between the a and b values, showing pertinence less than one, can also be between points b and c, having degree of pertinence equal to 1 . In the third case, the modeling number ( $\mathrm{x}$ ) can be between points $c$ and $d$, however, in this case with degree of pertinence less than one and not otherwise belonging to this fuzzy set. Thus, their representation in the determination of points can be established as follows:

$f(x, a, b, c, d)=\left\{\begin{array}{cc}\frac{x-a}{b-a} & \text { if } a \leq x<b \\ 1 & \text { if } b \leq x \leq c \\ \frac{d-x}{d-c} & \text { if } c<x \leq d \\ 0 & \text { oposite case }\end{array}\right\}$

Or, as

$\operatorname{trapmf}(x ; a, b, c, d)=\max \left(\min \left(\frac{x-a}{b-a}, 1, \frac{d-x}{d-c}, 0\right)\right.$

Based on literature survey data and interview with an expert in orchids cultivation, it was possible to determine the points of each relevance function on orchid growth physiology. Fig. 2(a) shows the set of humidity parameter, where its range is [0-100] and was ranked in "Low," "Medium," and "High." Table 1 contains the points that form the relevance functions. Parameter set "temperature" has been developed and the adopted range was from [0-45]. Thus, it was possible to draw up Fig. 2(b) and Table 1. Finally, the parameter "shade" was adopted the range from [0-100], and it was possible to draw up Fig. 2(c) and Table 1.

In this study, different situations of temperature, humidity, and shading conditions were combined and analyzed. To evaluate the vitality of Laelia purpurata a mathematical model was used as previously described in the literature $[8,10,15,17]$. It was possible to determine the points that formed sets of similar relevance not inferring unequally in the output model. Finally, Fig. 2(d) and Table 1
Table 1

Definition of relevance functions for the variable Input: (a) humidity, (b) temperature, (c) shade. Output: (d) vitality.

\begin{tabular}{|c|c|c|}
\hline Fuzzy set & Type & Limiter \\
\hline \multicolumn{3}{|l|}{ Humidity } \\
\hline “Low" (B) & Trapezoid & {$\left[\begin{array}{llll}-1 & 0 & 20 & 40\end{array}\right]$} \\
\hline “Medium” (M) & Trapezoid & {$\left[\begin{array}{llll}20 & 40 & 60 & 80\end{array}\right]$} \\
\hline "High" (A) & Trapezoid & {$\left[\begin{array}{lllll}60 & 80 & 100 & 101\end{array}\right]$} \\
\hline \multicolumn{3}{|l|}{ Temparature } \\
\hline “Low” (B) & Trapezoid & {$\left[\begin{array}{llll}-1 & 0 & 10 & 15\end{array}\right]$} \\
\hline "Medium" (M) & Trapezoid & {$\left[\begin{array}{llll}5 & 15 & 20 & 30\end{array}\right]$} \\
\hline "High" (A) & Trapezoid & {$\left[\begin{array}{llll}20 & 30 & 45 & 50\end{array}\right]$} \\
\hline \multicolumn{3}{|l|}{ Shade } \\
\hline "Low" (B) & Trapezoid & {$\left[\begin{array}{llll}-1 & 0 & 20 & 40\end{array}\right]$} \\
\hline "Medium" (M) & Trapezoid & {$\left[\begin{array}{llll}20 & 40 & 60 & 80\end{array}\right]$} \\
\hline "High" (A) & Trapezoid & {$\left[\begin{array}{lllll}60 & 80 & 100 & 101\end{array}\right]$} \\
\hline \multicolumn{3}{|l|}{ Shade } \\
\hline “Bad” (B) & Trapezoid & {$\left[\begin{array}{llll}-1 & 0 & 0.2 & 0.4\end{array}\right]$} \\
\hline "Medium" (M) & Trapezoid & {$\left[\begin{array}{llll}0.2 & 0.4 & 0.6 & 0.8\end{array}\right]$} \\
\hline "Good" (A) & Trapezoid & {$\left[\begin{array}{llll}0.6 & 0.8 & 1 & 2\end{array}\right]$} \\
\hline
\end{tabular}

were developed based on number of membership ranging from 0 to 1 .

The defuzzification process adopted in this study was the gravity method (centroid), which according to Barros and Bassanezi [4] it is the most appropriate and accurate method. The equation that relates the discrete domain is:

$G(B)=\frac{\sum_{i=0}^{n} \mu_{i} \varphi B\left(\mu_{i}\right)}{\sum_{i=0}^{n} \varphi B\left(\mu_{i}\right)}$

where; $G(B)$ is a real number representing the fuzzy system output, and $\mu_{\mathrm{i}}$ is the universe value corresponding to the gravity center of fuzzy set, which is associated to activation degree of the rule $\mathrm{R}_{1}$.

A system based on computer fuzzy rules was established by Fuzzy Logic Toolbox of MAT LAB ${ }^{\circledR} 14$ a, coupled to surface and representation contour map of the system [17].

In order to establish and recommend the appropriate sites of Brazil to cultivate Laelia purpurata a fuzzy model based on climate data was developed. The climate data related to average temperature and humidity were collected from National Institute of Meteorology data base [13]. To establish the good practice for orchid cultivation under different environments, the Pearson correlation between parameters was calculated combined with and simulating various shading conditions.

\section{Results and discussion}

From the literature review regarding the cultivation of Laelia purpurata, it was possible to draft the base rule (Table 2).

The rule base for fuzzy mathematical modeling was elaborated based on an interview with a orchid farmer specialist and also based on the literature review. In this way, the construction of rule base was tested and performed simulations to reached the high precision levels. Thus, the vitality of orchid plants was accurately classified based of temperature, humidity and shading effects on Laelia purpurata cultivation.

For the example the first 3 rows on Table 2 represent the relationship:\%

- If (humidity is "B") (temperature is "B") (shading is "B") then (vitality is "B");

- If (humidity is "M"), (temperature is "B") (shading is "B") then (vitality is "B");

- If (humidity is "A") (temperature is "B") (shading is "B") then (vitality is "B"); 
a

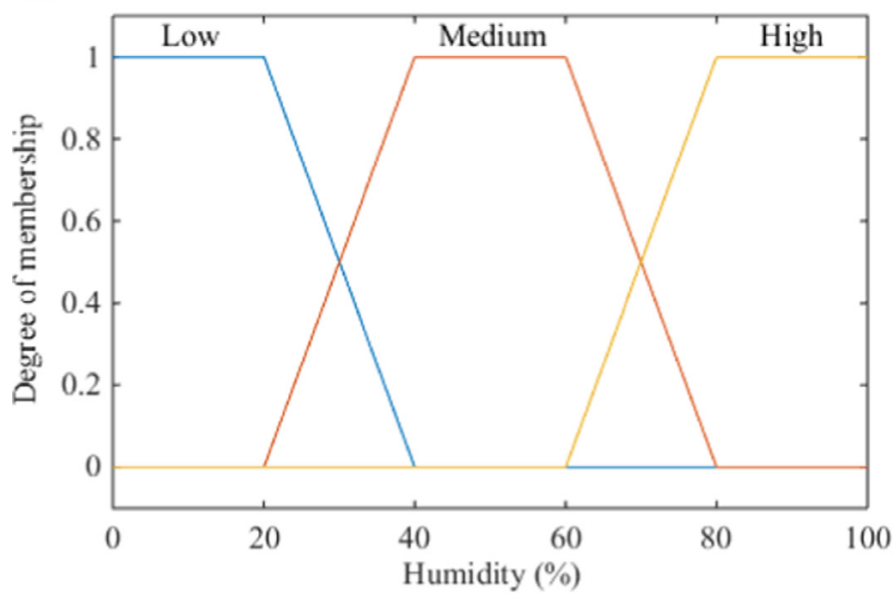

C

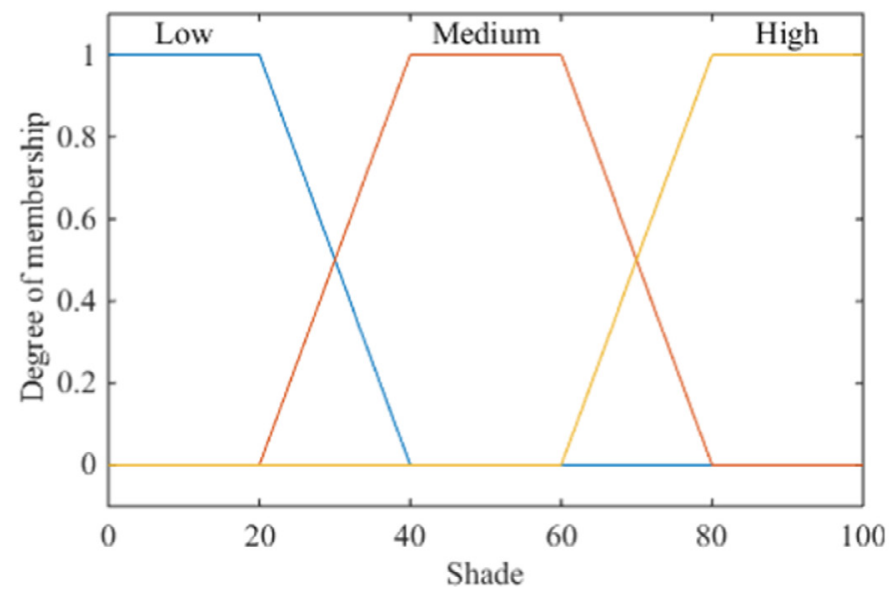

b

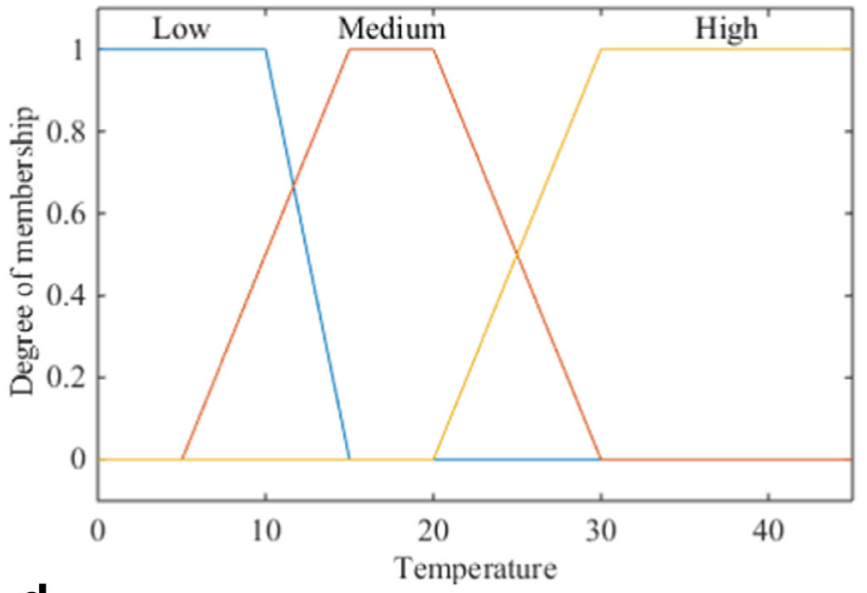

d

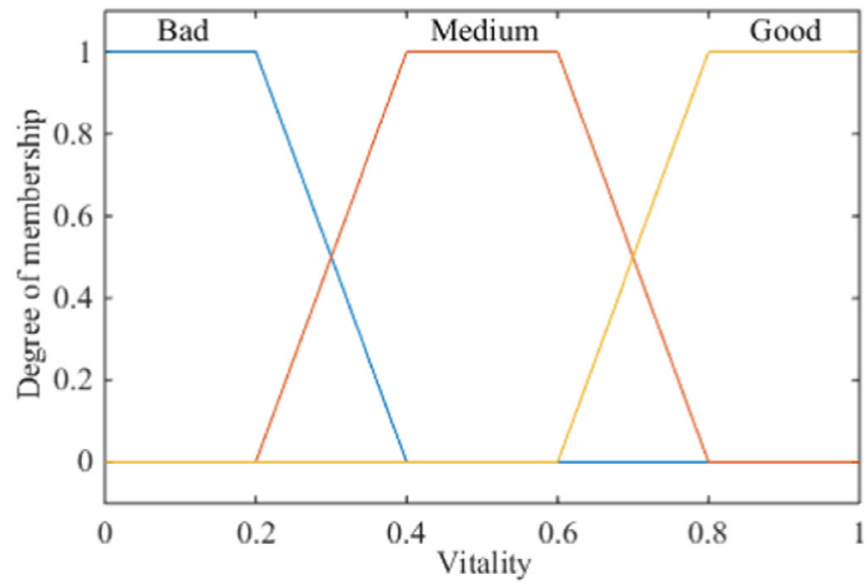

Fig. 2. System parameter for the determination of vitality. Input: (a) humidity, (b) temperature, (c) shade. Output: (d) vitality.

Table 2

Basic rules of the fuzzy system.

\begin{tabular}{llll}
\hline Humidity & Temperature & Shading & Vitality \\
\hline B & B & B & B \\
M & B & B & B \\
A & B & B & B \\
B & M & B & B \\
M & M & B & M \\
A & M & B & M \\
B & A & B & B \\
M & A & B & B \\
A & A & B & B \\
B & B & M & B \\
M & B & M & B \\
A & B & M & M \\
B & M & M & M \\
M & M & M & M \\
A & M & M & A \\
B & A & M & A \\
M & A & M & A \\
A & A & M & A \\
B & B & A & B \\
M & B & A & B \\
A & B & A & B \\
B & M & A & M \\
M & M & A & M \\
A & M & A & M \\
B & A & A & M \\
M & A & A & M \\
A & A & A & B \\
\hline & & &
\end{tabular}

The other lines are interpreted analogously.

From the developed model it was possible to prepare the surfaces response for vitality of orchids and their contour maps to verify the real inference of humidity, temperature, and shading.

The model based on fuzzy rules verified all combinations between variables. Fig. 3(a) is the fuzzy response surface model, and Fig. 3(b) the contour map.

In this study, it was observed a strong relationship between humidity and temperature determining the vitality of orchid. In other words, higher temperatures and humidity do not provide an adequate vitality of plants (Fig. 3).

The region A illustrates in Fig. 3(b) represents an unfavorable vitality condition due to low humidity and low temperature not providing optimal conditions to orchid plant growth and develop. On the other hand, region B (Fig. 3-b) characterized by being an area that presents average temperature and high humidity, providing an adequate region condition for naturally orchid cultivation.

Bahuguna and Jagadish [2] observed that plants showing thermo sensor that can lead to adaptation to higher temperature and low humidity over time.

The surface map representing the vitality of orchids is shown in Fig. 4(a) and the contour map Fig. 4(b).

The humidity and shading effect directly determine the vitality of orchid plants. The average values for humidity and shading conditions provide the best conditions for cultivation of orchid plants as illustrated in Fig. 4(a). The contour map (Fig. 4(b)) shows a plan where on Region A occurs the worst conditions of vitality due to 
a

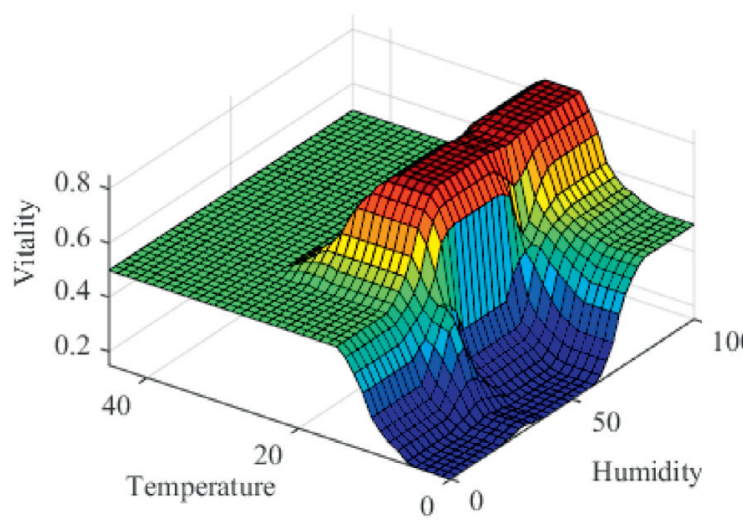

b

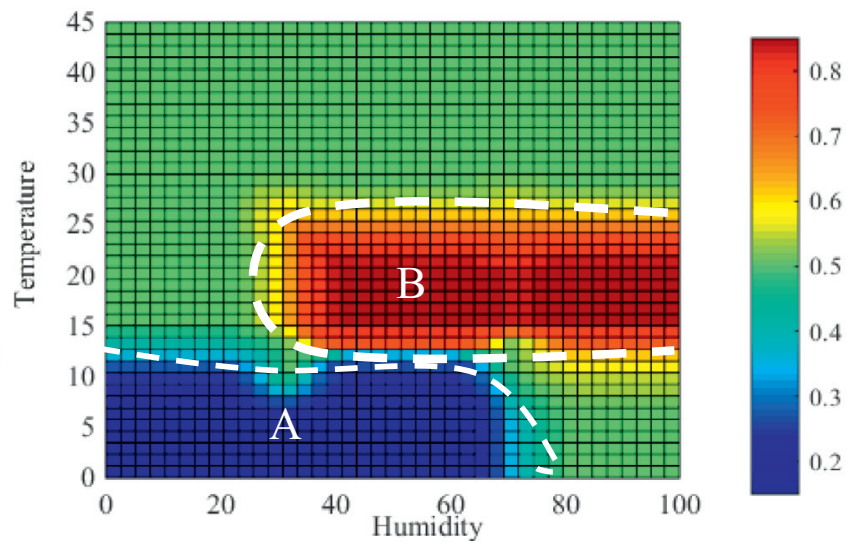

Fig. 3. Vitality response of Laelia purpurata in response to temperature and humidity, (a) surface and (b) Contour map.

a

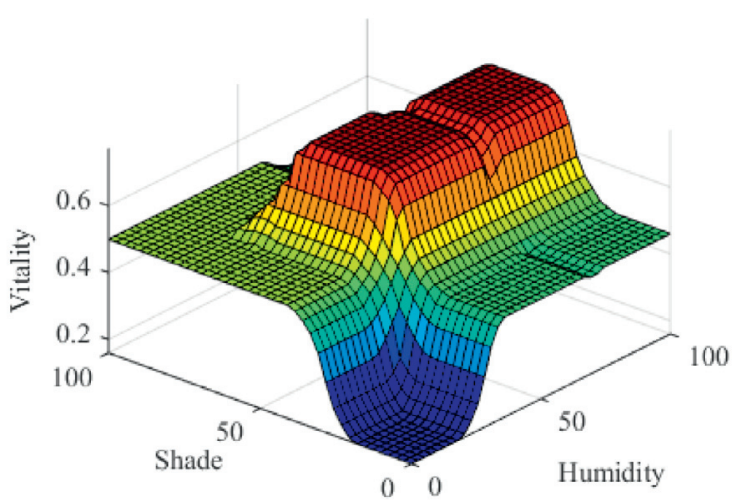

b

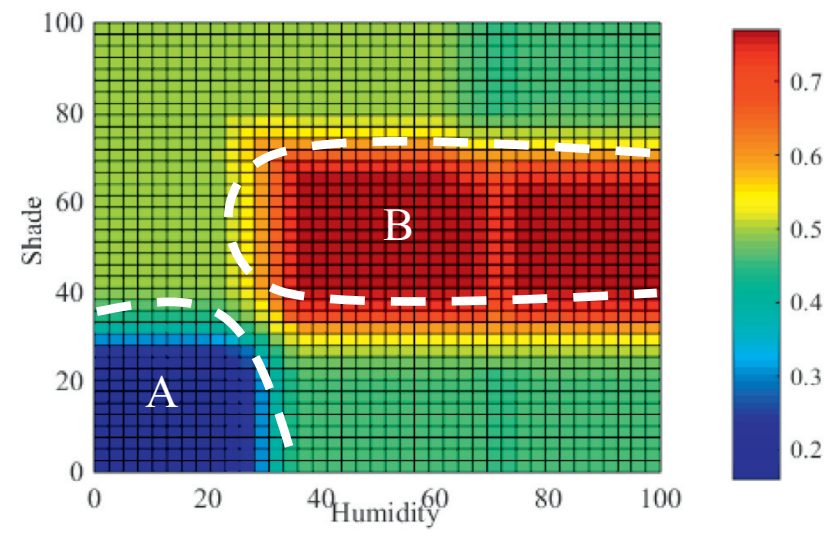

Fig. 4. Vitality response of Laelia purpurata in response to shade and humidity (a) surface and (b) contour map.

low humidity and shading. This environment conditions is not appropriate for growth development of plants. On the other hand, Region B (Fig. 4-b) shows a track with average shading ranges from low to high humidity making the best conditions for vitality of orchid plants.

The high humidity can lead to a reduced activity of the stomata and hinder the development of plants [9]. Aasamaa and Sober [1] found on six different humidity conditions that plants showed deregulation of stomata, which leads the leaf dehydration. Rosenvald et al. [19] observed that increase on global warming could lower the air humidity level affecting the rate of photosynthesis.

The temperature and shade show strong influence on the development of Laelia purpurata orchid. Using the fuzzy mathematical models, it was possible to analyze the effect on the vitality and draw up surface response (Fig. 5(a)) and the contour map (Fig. 5(b)).

The temperature directly affects the rate of rubisco activity, impairing photosynthesis in C3 plants [14]. High temperature induce plant to photorespiration, which refers to a process in C3 plant metabolism where enzyme rubisco oxygenates RuBP, causing some of the energy produced in photosynthesis to be wasted. In this study, we observed that the highest and lowest temperature affect negatively the vitality of orchids plants (Fig. 5(a)). Region A is characterized by low temperature associated with different shading levels showing a negatively effect on vitality of orchids. In addition, higher temperatures associated with low shade condition also promote a negative effect on vitality of orchids as characterized in Region C (Fig. 5b).

According to results obtained in Fig. 5(b), Region B provides higher vitality for orchid plants. This happens because the plants are growing in a region showing intermediate values for temperature and shading. It is known that in order to reduce the incidence of high irradiance in plants, artificial shade can be used in orchidarium. Gonçalves et al. [12] observed that plants germinating under larger tree canopy have difficulties to carry out photosynthesis. In addition, Costa et al., [7] concluded that the lack of illumination impairs the development of andiroba species.

Is known that the species of Laelia purpurata grown naturally in the states of Santa Catarina, Rio Grande do Sul and São Paulo. Therefore, in order to investigate the temperature, humidity, and shading effects on vitality, it was simulated in the model the first condition with the shading at 75 and 100\% (Fig. 6(a) and (b)), respectively.

In this study, it was observed that the average temperature of capitals from each state and the vitality showed a strong negative correlation $(r=-0.72)$. In other words, these results suggest that the increase in temperature causes reduction on vitality, justifying the need to cover with artificial shade. There was no statistical significant correlation between humidity and vitality $(\mathrm{r}=-0.12)$, showing that humidity is not an intrinsic factor driving the vitality of orchids. It is interesting to note that the North and Northeast capitals show higher average temperature. Therefore, these regions 
a

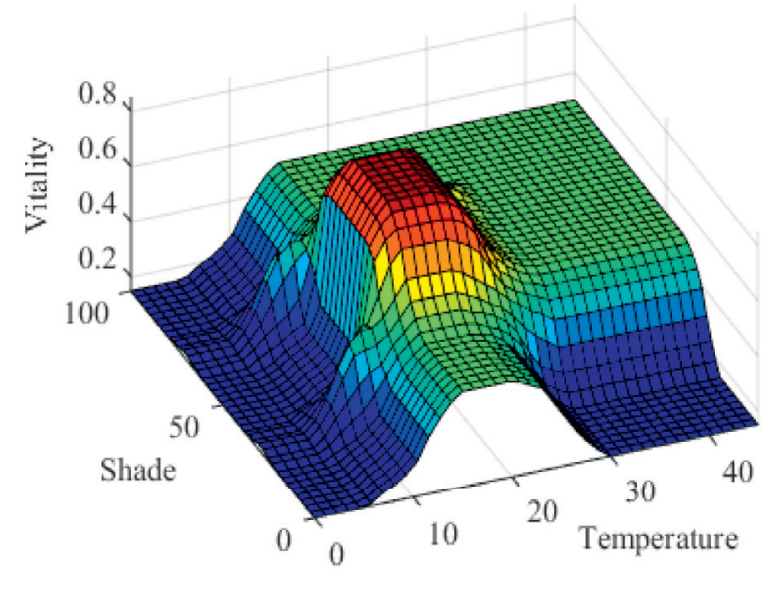

b

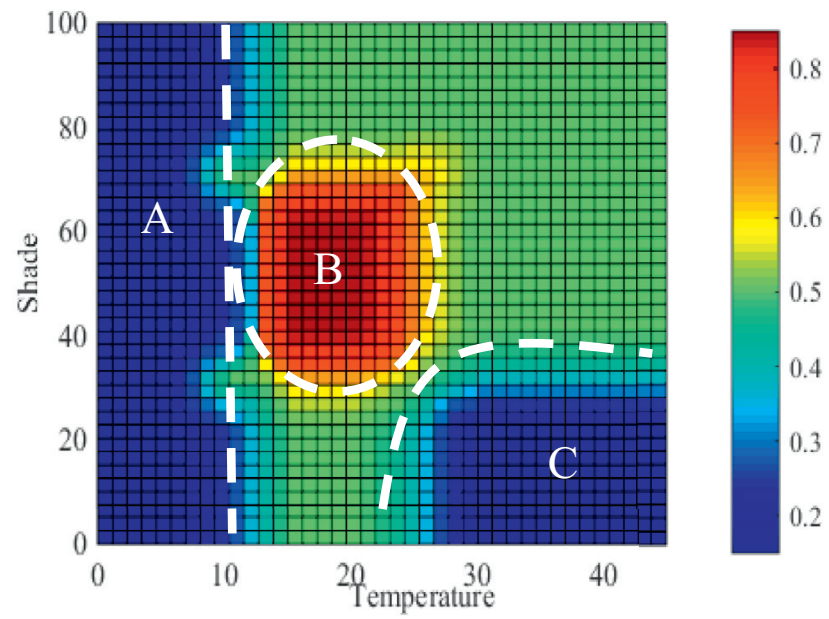

Fig. 5. Vitality response of Laelia purpurata in response to temperature and shade, (a) surface and (b) contour map.

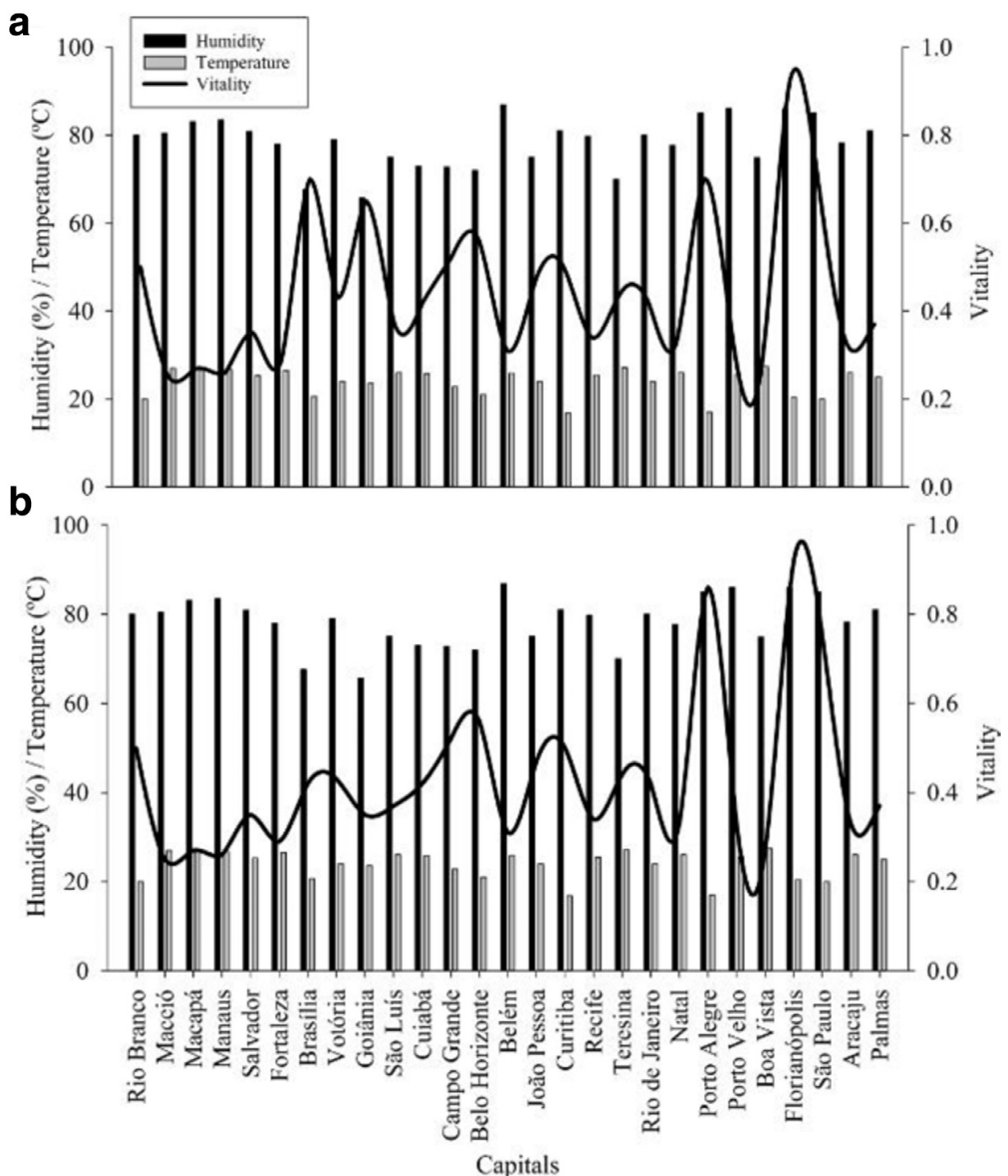

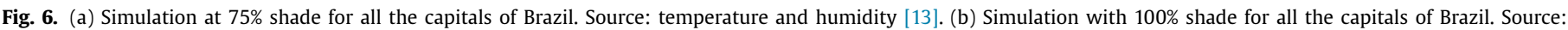
temperature and humidity [13]. 
are not recommended for orchid cultivation due to inappropriate climatic conditions.

The mathematical simulation set at $75 \%$ of shading showed the best results for cultivation of orchids. According to the calculated results, the cities of Santa Catarina, São Paulo, and Rio Grande do Sul showed the best growing environmental conditions (Fig. 6(b)).

The increase in global average temperature impairs the vitality of orchids, which impairs the photosynthesis rate directly affecting survival on native places or in commercial cultivation. Laelia purpurata is a specie commercialized in large scale due to the long flower duration and also because it shows great greed by collectors.

\section{Conclusions}

From the fuzzy model, we found that the increase in temperature and lack of proper shading can reduce the vitality of orchids and thereby damage its flowering and consequently harming its sale to intend for decoration and collectors.

Another important fact that reduces more severely vitality is the issue of global warming, which in general has caused severe damage to ecosystems throughout the world. Fuzzy mathematical model could precisely detect the effect of higher temperatures causing damages on vitality of plants as a consequence of global warming.

\section{References}

[1] K. Aasamaa, A. Sõber, Stomatal sensitivities to changes in leaf water potential, air humidity, $\mathrm{CO}_{2}$ concentration and light intensity, and the effect of abscisic acid on the sensitivities in six temperate deciduous tree species, Environ. Exp. Bot. 71 (1) (2011) 72-78. 2011 http://dx.doi.org/10.1016/j.envexpbot.2010. 10.013.

[2] R.N. Bahuguna, K.S. Jagadish, Temperature regulation of plant phenological development, Environ. Exp. Bot. 111 (2015) 83-90. http://dx.doi.org/10.1016/j. envexpbot.2014.10.007.

[3] D. Barman, R. Devadas, Climate change on orchid population and conservation strategies: a review, J. Crop. We. 9 (2) (2013) 1-12.

[4] R.C. Barros, L.C. Bassanezi, Tópicos De Lógica Fuzzy e Biomatemática, UNICAMP/IMECC, Campinas, 2010

[5] J. Cail, et al., The genome sequence of the orchid Phalaenopsis equestris, Nat. Genet. 47 (1) (2015) 65-72. http://dx.doi.org/, doi:10.1038/ng.3149.

[6] F.J. Chang, H.C. Lai, Adaptive neuro-fuzzy inference system for the prediction of monthly shoreline changes in northeastern Taiwan, Ocean. Eng. 84 (2014) 145-156. http://dx.doi.org/10.1016/j.oceaneng.2014.03.020.

[7] G.F.da Costa, RicardoA. Marenco, Fotossíntese, condutância estomática e potencial hídrico foliar em árvores jovens de andiroba (Carapa guianensis), Acta Amazôn. 37 (2) (2007) 229-234.
[8] C.P. Cremasco, L.R.A. Gabriel Filho, A. Cataneo, Metodologia de determinação de funções de pertinência de controladores fuzzy para a avaliação energética de empresas de avicultura de postura, Eng. Agri. 25 (1) (2010) 21-39.

[9] D. Fanourakis, E. Heuvelink, S.M. Carvalho, A comprehensive analysis of the physiological and anatomical components involved in higher water loss rates after leaf development at high humidity, J. Plant. Physiol. 170 (10) (2013) 890898. http://dx.doi.org/10.1016/j.jplph.2013.01.013.

[10] L.R. Gabriel Filho, et al., Application of fuzzy logic for the evaluation of livestock slaughtering, Eng. Agri. 31 (4) (2011) 813-825. http://dx.doi.org/10.1590/ S0100-69162011000400019.

[11] E. Giusti, S.A. Marsili-Libelli, Fuzzy decision support system for irrigation and water conservation in agriculture, Environ. Modell. Softw. 63 (2015) 73-86. 2015. http://dx.doi.org/10.1016/j.envsoft.2014.09.020.

[12] C.J.F. Gonçalves, et al., Effect of light environment on growth of young plants of mahogany (Swietenia macrophylla King), Sci. Forest. 40 (95) (2012) 337-344.

[13] INMET - Instituto Nacional de Meteorologia. Disponível em: $<$ http.www.inmet.gov.br>Acesso em: 21. nov. 2015.

[14] B. Jurczyk, et al., Enhanced expression of Rubisco activase splicing variants differentially affects Rubisco activity during low temperature treatment in Lolium perenne, J. Plant. Physiol. 198 (2016) 49-55. 2016 http://dx.doi.org/doi:, doi:10.1016/j.jplph.2016.03.021.

[15] D.F. Pereira, et al., Sistema fuzzy para estimativa do bem-estar de matrizes pesadas, Eng. Agri. 28 (4) (2008) 624-633. 2008 http://dx.doi.org/10.1590/ S0100-69162008000400002.

[16] T. Prato, Increasing resilience of natural protected areas to future climate change: a fuzzy adaptive management approach, Ecol. Model. 242 (2012) 4653. http://dx.doi.org/10.1016/j.ecolmodel.2012.05.014.

[17] F.F. Putti, et al., Fuzzy logic to evaluate vitality of Catasetum fimbiratum species (Orchidacea), Irrig 19 (3) (2014) 405-413. http://dx.doi.org/10.15809/ irriga.2014v19n3p405.

[18] K.M. Robbirt, et al., Potential disruption of pollination in a sexually deceptive orchid by climatic change, Curr. Biol. 24 (23) (2014) 2845-2849. http://dx.doi. org/10.1016/j.cub.2014.10.033.

[19] K. Rosenvald, et al., The effect of elevated air humidity on young silver birch and hybrid aspen biomass allocation and accumulation-acclimation mechanisms and capacity, Forest. Ecol. Manag. 330 (2014) 252-260. http://dx.doi.org/ 10.1016/j.foreco.2014.07.016.

[20] N.D. Swarts, K.W. Dixon, Perspectives on orchid conservation in botanic gardens, Trends. Plant. Sci. 14 (11) (2009) 590-598. http://dx.doi.org/10.1016/j. tplants.2009.07.008.

[21] N.D. Swarts, K.W. Dixon, Terrestrial orchid conservation in the age of extinction, Ann. Bot-London 104 (3) (2009) 543-556. http://dx.doi.org/10.1093/aob/ mcp025.

[22] M. Waongo, P. Laux, H. Kunstmann, Adaptation to climate change: the impacts of optimized planting dates on attainable maize yields under rainfed conditions in Burkina Faso, Agr. Forest. Meteorol. 205 (2015) 23-39. http: //dx.doi.org/10.1016/j.agrformet.2015.02.006.

[23] Watanabe, D.; Morimoto, M.S. Orquídeas: manual de cultivo. São Paulo, Associação Orquidófila de São Paulo, 2002.

[24] P. Willmer, Climate change: bees and orchids lose touch, Curr. Biol. 24 (23) (2014) 1133-1135. http://dx.doi.org/10.1016/j.cub.2014.10.061.

[25] C.T. Yeh, Weighted trapezoidal and triangular approximations of fuzzy numbers, Fuzzy Set. Syst. 160 (21) (2009) 3059-3079. http://doi:10.1016/j.fss.2009. 05.008 . 